Phosphaten etc. zu erkennen gab, ein blauer Farbestoff enthalten war, der aber erst auf Zusatz gleicher Mengen rauchender Salzsäure, verdünnter Schwefelsäure oder Salpetersäure sich abschied. Der ausgewaschene und getrocknete Farbestoff bildete ein tiefblaues Pulver mit kupferrothem Strich, war unlöslich in kaltem und kochendem Wasser, verdünnten Säuren und Alkalien, wurde jedoch von kochendem Alkohol und noch leichter von Aether mit blauer Farbe aufgenommen, nach dem Erkalten als schwarzblaues Pulver wieder niederfallend. Er war sublimationsfähig wie der Indigo; bei $280^{\circ}$ verwandelte er sich in einen purpurfarbenen Rauch und sublimirte grösstentheils unzersetzt in purpurfarbenen, glänzenden und durchscheinenden Prismen und Nadeln, die unlöslich in Wasser, Alkohol und Aether und vom sublimirten Indigo nicht zu unterscheiden waren. Gegen concentrirte Schwefelsäure, Chlor, schweflige Säure, Salpetersäure verhielt sich der Farbestoff ebenfalls so wie Indigo, auch liess er sich durch leicht oxydirbare Stoffe, wie Eisenoxydul, schweflige Säure, Schwefelammonium etc. bei Gegenwart von Alkalien oder alkalischen Erden entfïrben, d. $h$. reduciren und aus der entfärbten Lösung in Alkali durch Berührung mit atmosphärischer Luft oder verdünnter Salzsäure in der ursprünglichen Farbe wieder herstellen. Im reducirten Zustande entspricht er also wahrscheinlich dem Indigweiss. Aus allem hier Mitgetheilten folgert v. Sicherer die Identität des Farbestoffs mit dem Cyanurin oder Urocyan Heller's, aber auch die Uebereinstimmung beider mit dem Indigo, die indessen ganz bestimmt erst durch die Elementaranalyse wird festgestellt werden müssen, welche bis jetzt noch nicht ausgeführt ist. (Annal. der Chem. $u$. Pharm. XC: p. 120-123.)

$\boldsymbol{G}$.

\title{
Filtration der Luft in Beziehung auf Fäulniss und Gährung.
}

Schröder und v. Dasch haben in folgender Weise einen Luftfiltrationsapparat eingerichtet:

Ein Glaskolben, zur Aufnahme der dem Einfluss der Luft auszusetzenden Probesubstanz bestimmt, wird mit einem in heissem Wachs getränkten, vollkommen luftdicht schliessenden Korke versehen, durch welchen zwei unter einem rechten Winkel gebogene, ebenfalls luftdicht schliessende Glasröhren gehen, eine Zuleitungsröhre und eine Saugröhre. Die Zuleitungsröhre wird mittelst eines kurzen 
Schlauches von vulkanisirtem Kautschuk mit einer kurzen Glasröhre verbunden, welche lufttdicht durch den ebenso schliessenden, mit Wachs getränkten Kork eines weiteren Glasrohres von etwa 1 Zoll Durchmesser und 20 Zoll Länge hindurchgeht. Dieses weitere Rohr wird lose mit Baumwolle gefüllt, welche vorher einige Zeit hindurch im Wasserbade erwärmt ist. Das andere Ende dieser weiteren, mit Baumwolle gefüllten Glasröhre, der Filtrationsröhre, wird ebenfalls mit einem in Wachs getränkten Korke luftdicht verschlossen, durch welchen gleichfalls eine enge, kurze und offene Glasröhro eingeführt ist, welche die offene Röhre genannt werden kann. Das zweite unter einem rechten Winkel gebogene Glasrohr des Kolbens, das Saugrohr, welches im Kolben fast bis auf das Niveau der Probesubstanz hinabreicht, wird mittelst eines vulkanisirten Kautschukrohres mit dem oberen seitlichen, mit einem Hahne versehenen Ausflussrohre eines gewöhnlichen Gasometers luftdicht in Verbindung gesetzt, der Gasometer mit Wasser gefüllt und nach Oeffnung des unteren, schief einmündenden Kupferrohres, welches gewöhnlich zur Aufnahme der Entwickelungsröhren bestimmt ist, der Hahn geöffnet, welcher die Verbindung des Saugrohres mit dem Gasometer abschliesst. Der Gasometer wirkt nun als Aspirator; indem Wasser unten ausfliesst, wird Luft durch das Filtrationsrohr in den Kolben mit der Probesubstanz nachgesaugt. Schliesst man die offene Glasröhre am freien Ende der Filtrationsröhre, so muss in kurzer Zeit der Ausfluss des Wassers aufhören, wenn alle Verbindungen luftdicht hergestellt sind, und man kann sich dadurch überzeugen, dass keine Luft in den Kolben gelangt, welche nicht vorher durch die Baumwolle des Filtrationsrohres gegangen ist.

Mittelst dieses Apparnts stellten nun Schröder und v. Dasch die Versuche in der Art an, dass nach Herstellung aller Verbindungen der Hahn des Aspirators geschlossen und die in dem Kolben befindliche Probesubstanz (Fleischbrühe mit Fleisch, Malzwürze u. s. w.) bis zum Kochen erhitzt und so lange im Kochen erhalten wurden, bis alle Verbindungsröluren bis an die Baumwolle im Filtrationsrohre hin heiss geworden waren. Hierauf wurde nach einiger Zeit der Hahn des Aspirators geöffnet und so regulirt, dass das Wasser tropfenweise ausfloss und also die Luft langsam nachgesaugt wurde. Der Aspirator, I Cubikfuss Wasser fassend, wurde täglich zweimal, Morgens und Abends, nach vorherigem Schliessen des Hahns 
des Saugerohres nachgefüllt und dann wieder in Gang gesetzt. Aus den mit verschiedenen Substanzen lange Zeit hindurch fortgesetzten Versuchen ergab sich

1) dass mit Wasser frisch abgekochtes Fleisch nicht fault, und dass frisch gekochte Fleischbrïhe während mehrerer Wochen völlig unverändert blieb, wenn nur solche Luft Zutritt hatte, welche vorher durch Baumwolle filtrirt war;

2) dass eine süsse, gährungsfähige Malzwürze durch Wochen selbst in den Sommermonaten unveründert bleibt, wenn keine andere, als durch Baumwolle filtrirte Luft Zutritt hat;

3) dass sich heraùszustellen scheint, dass es freiwillige Zersetzungen organischer Substanzen gebe, wie das Faulen von Fleisch ohne Wasser und des Käsestoffs der Milch, ferner die Verwandlang des Milchzuckers in Milchsäure in der Milch, welche zu ihrem Beginne lediglich des Sauerstoffs der Luft bedürfen, dass es aber auch andere Gährungs- und Fäulnisserscheinungen gebe, welche mit jenen mit Unrecht in eine Kategorie gestellt werden, wie die Gährung von Malzwürze und das Faulen von Fleisch unter Fleischbrühe, welche zu ihrem Beginne ausser dem Sauerstoffe auch noch die unbekannten Beimischungen der atmosphärischen Luft erfordern, welche nach Schwan's Versuchen (Poggd. Annal. XLI. p. 184) durch Erhitzen der Luft, nach den hier mitgetheilten Versuchen aber auch durch Filtration der Luft durch Baumwolle aus ihr entfernt werden können.

Bei weiter fortgesetzten Versuchen in dieser Beziehung wird die Aufmerksamkeit auf gewisse einfache organische Verbindungen (Eiweissstoff, Faserstoff etc.), aber auch auf anderweitige Filtrationsmittel (Kohle, Bimsstein, Glas, Gyps etc.) zu richten sein. (Ann. der Chem. u. Pharm. XIII. p. 232-243.)

G.

\section{Benzoëoxyd.}

Der unter den Destillationsproducten des benzoësauren Kupferoxyds von Ettling und Stenhouse entdeckte krystallisirte Körper, der von ihnen Benzoëoxyd genannt wurrle, mit der Formel $\mathrm{C}^{14} \mathrm{H}^{5} \mathrm{O}^{2}$ ist bisher von Einigen als eine unter der Benzoësäure stehende Oxydationsstufe des Radicals Benzoyl $\left(\mathrm{C}^{14} \mathrm{H}^{5}\right)$, von Anderen als das Radical Benzoyl $\left(\mathrm{C}^{1} \mathrm{H}^{5} \mathrm{O}^{2}\right)$ selbst angesehen worden. K. Lis $t$ und $H$. Limprecht, von der Ansicht ausgehend, dass viele 